Supplement of Hydrol. Earth Syst. Sci., 22, 2921-2935, 2018

https://doi.org/10.5194/hess-22-2921-2018-supplement

(C) Author(s) 2018. This work is distributed under

the Creative Commons Attribution 4.0 License.

(c) (1)

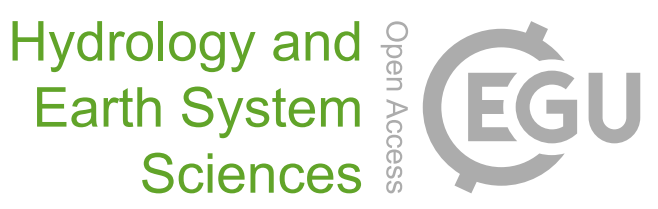

Supplement of

\title{
Dendrohydrology and water resources management in south-central Chile: lessons from the Río Imperial streamflow reconstruction
}

\author{
Alfonso Fernández et al. \\ Correspondence to: Alfonso Fernández (alfernandez@udec.cl)
}

The copyright of individual parts of the supplement might differ from the CC BY 4.0 License. 


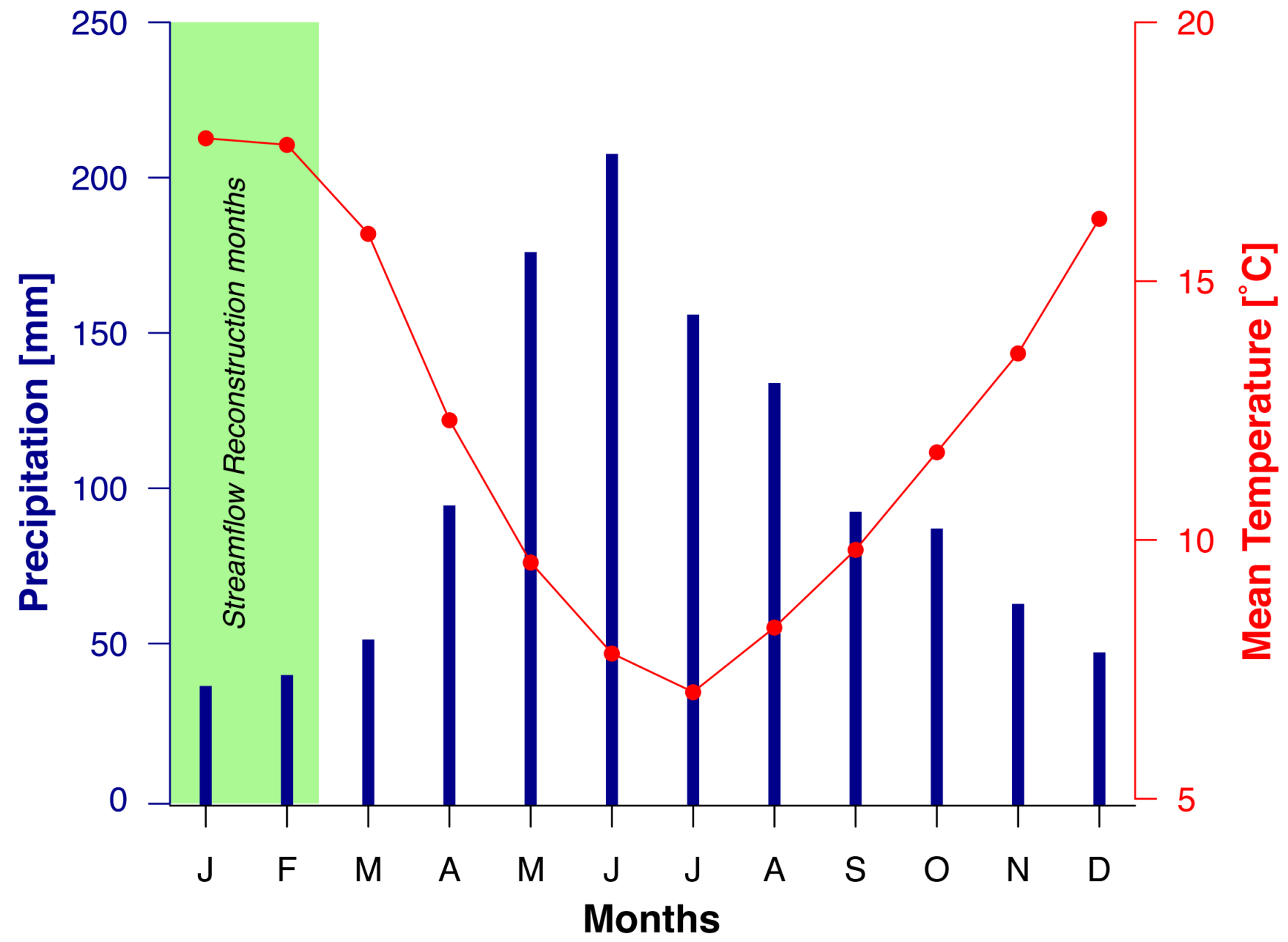

Figure S1. Climograph showing the distribution of mean temperature and precipitation for TEM during the period 1980-2010. The lowest amounts of precipitation occur in January and February, corresponding to the base flow for the Río Imperial. 

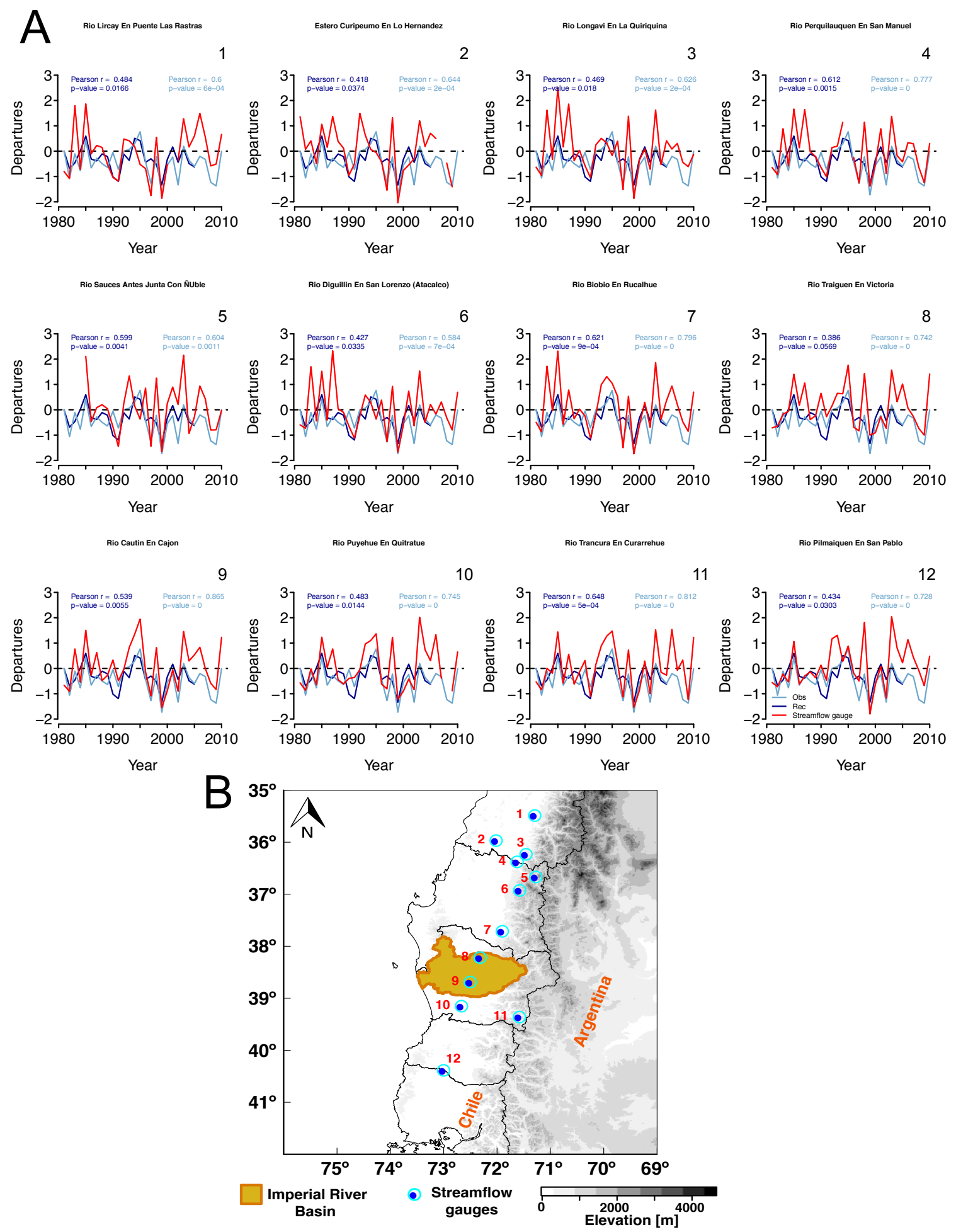

Figure S2. (A) corresponds to a comparison between available summer streamflow data (red), the composite streamflow time series (cyan) and our tree-ring reconstruction (red) for the period 1980-2010. The locations of the gauges is denoted in (B). 


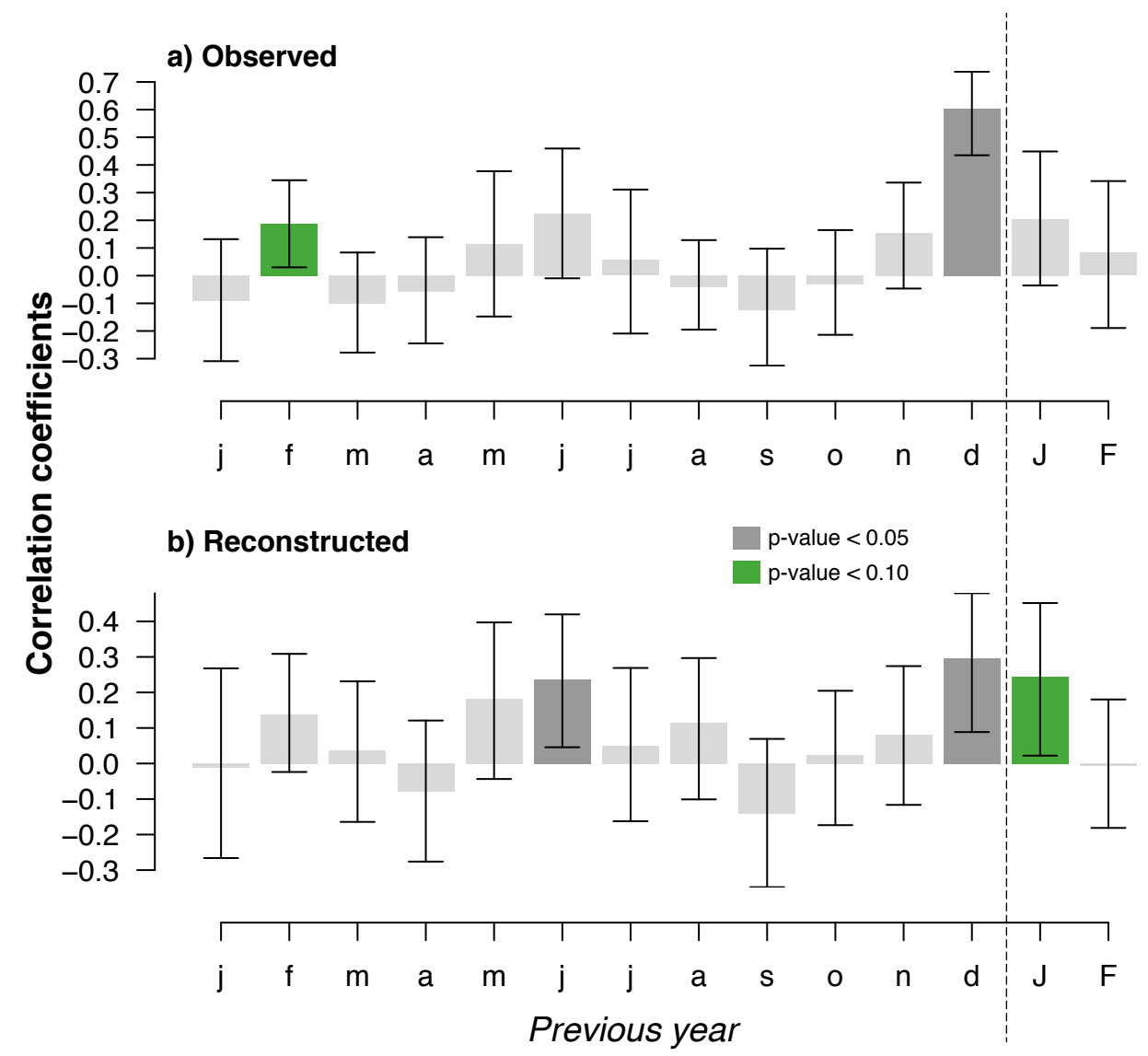

Figure S3. Correlation of observed/reconstructed streamflow with TEM rainfall for each month of the previous year. 


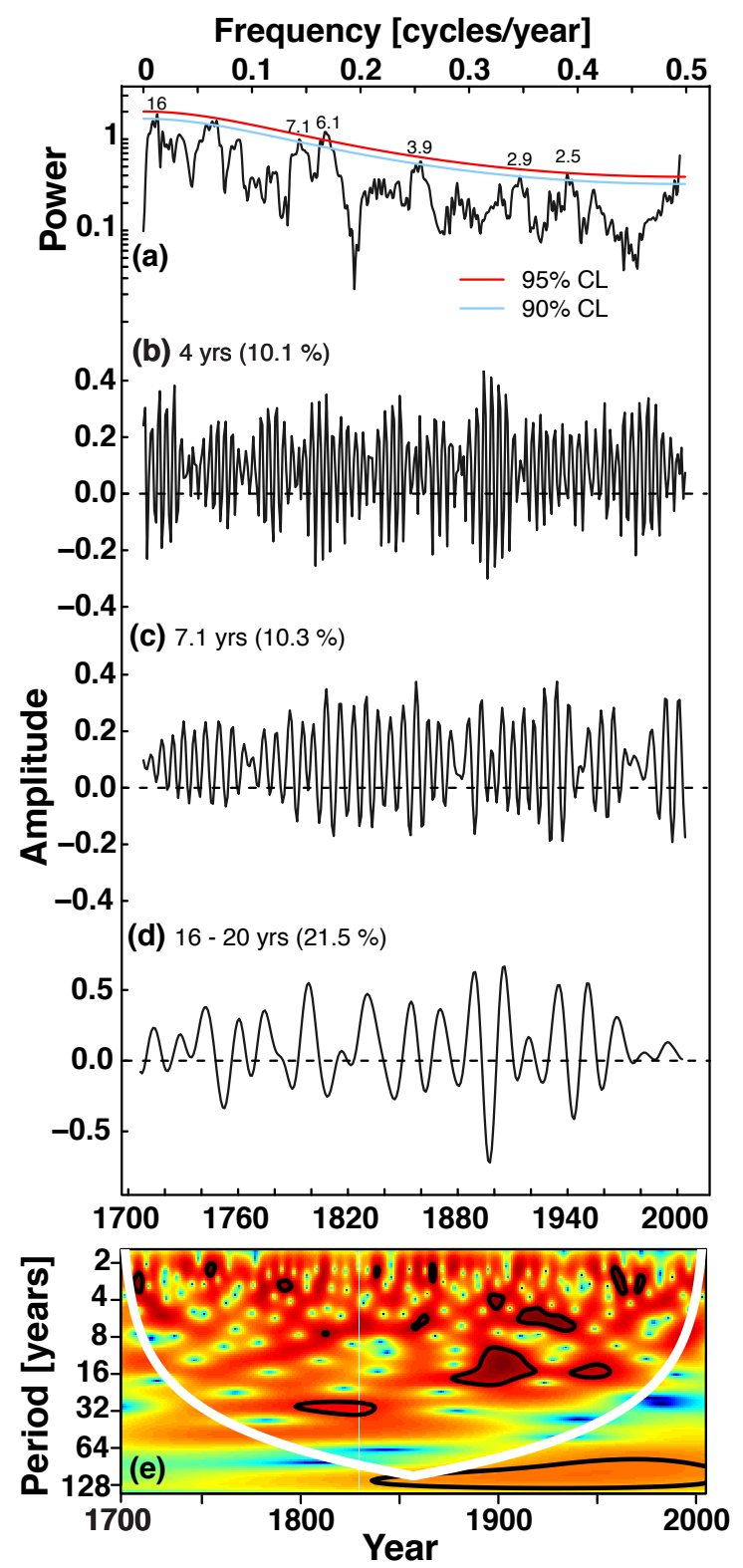

Figure S4. Spectral analyses of the time series demonstrating that the reconstruction captures high-frequency oscillations. 